\title{
Pragmatism and Embodiment as Resources for Feminist Interventions in Science
}

\author{
Sharyn Clough \\ School of History, Philosophy, and Religion \\ Oregon State University \\ sharyn.clough@oregonstate.edu
}

To appear in Contemporary Pragmatism

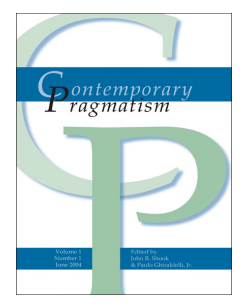

Dec. 2013, Vol. 10 (2).

\begin{abstract}
:
Feminist theorists have shown that knowledge is embodied in ways that make a difference in science. Intemann properly endorses feminist standpoint theory over Longino's empiricism, insofar as the former better addresses embodiment. I argue that a pragmatist analysis further improves standpoint theory: Pragmatism avoids the radical subjectivity that otherwise leaves us unable to account for our ability to share scientific knowledge across bodies of different kinds; and it allows us to argue for the inclusion, not just of the knowledge produced from marginalised bodies, but of the marginalised themselves.
\end{abstract}

\section{Introduction:}

Feminist philosopher of science and archaeologist Alison Wylie has analysed the growth in the late 1980's of a meta-research programme revealing of sexist/ethnocentric neglect or misreading of data within mainstream archaeological studies, e.g., human skeletal remains from Australia mistakenly presumed to be male because of their "robustness" relative to current notions of (white) womanly form in western industrialised nations, and edgewear patterns in stone tools misattributed to the technological needs of (presumed male) hunters, now found to be explained better by foraging activities (presumed to be associated with females), activities that have since come to be identified as providing the majority of the calories available in the prehistoric diet (Wylie and Nelson 2007; Wylie 2012). Wylie argues that this meta-archaeological research resulted largely "from the critical insights of women whose dissident experience put them in a position to recognize, and counteract, the unremarked androcentrism of mainstream archaeology" $(2012,65)$.

Many feminist philosophers such as Wylie make use of standpoint theory to explain the fact that when power is distributed inequitably across bodies of different kinds, as we know it to be in the contemporary west, for example, then knowledge too becomes embodied. Further, the embodiment of knowledge can make a difference even 
to the practice of science, a domain where these kinds of embodied differences are not supposed to matter. Because scientists are no different than anyone else in being marked and identified in terms of intersecting, normative social axes such as gender and ethnicity, then this embodiment makes a difference to the kinds of scientific knowledge claims that get made, justified, funded, and researched.

I agree that the standpoint account provides explanatory power in the scientific context as elsewhere, but I argue that it introduces new problems. I augment the standpoint account of embodiment with a pragmatist analysis to address these problems. I argue that the addition of a pragmatist analysis avoids the radical epistemic subjectivity of standpoint theory that otherwise leaves us unable to account for our ability to share scientific knowledge across bodies of different kinds; and also better allows us to argue for the inclusion in science, not just of the knowledge claims produced from marginalised standpoints, but of the marginalised themselves.

Some context. I place my discussion of feminist interventions in science against the following set of social conditions-the existence of which I believe to be too welldocumented to need arguing for here: Across the globe, power, including the power associated with the practices and knowledge claims of science, is differentially defined, produced, and distributed according to complex social hierarchies. These hierarchies are calibrated in terms of a normative matrix of embodied markers, such as (presumed) primary and secondary sex characteristics, gender roles, ethnic, and national backgrounds, dis/ability, and social/economic status.

The feminism I reference involves a charge of inequity directed at these social conditions. That this charge of inequity is a normative claim is probably obvious, but it is also an empirical claim. In other words, that the claim has any meaning and persuasive force, can best be understood by examining the empirical conditions that gave rise to it (Clough 2010; Clough and Loges 2008). The normative feminist charge of inequity is an empirical inference, that upon examination is well-supported by other broadly empirical claims such as the following:

1) the embodied markers according to which the complex social hierarchies are calibrated (as above) are socially and historically contingent features of human lives, always and already in play, even within feminist theorising;

2) these embodied markers are irrelevant and arbitrary when used as criteria for considering the limits and possibilities of human flourishing; and

3 ) when power is distributed under these social conditions, those who are relatively powerless are actively discouraged, via a variety of social and psychological mechanisms, from investigation of, and commitment to, 1) and 2).

Feminism, as I use the term, involves not only the normative charge of inequity directed at the social conditions at issue, but a call to respond to that inequity-a call to the institutions and persons benefiting from these social conditions to work for change: to more equitably define, produce, and distribute power, including the power associated with the practices and knowledge claims of science. This feminist call to respond is a normative claim, but it too is best understood as an empirical claim, one that has meaning and persuasive force in terms of empirical evidence that human flourishing, for people described as men and/or women, has been reliably associated with societies 
that reduce the inequities feminism targets. One could ask for empirical evidence supporting the appeal of human flourishing, but l'll invoke the later Wittgenstein and simply say that here my spade is turned. In other contexts it might make sense to muster an argument in support of human flourishing, but not here.

This is to acknowledge that all of these normative feminist claims - the charge of inequity, the call to respond to the inequity, and the evidence of human flourishingcan be understood as contingent empirical claims about the human condition that may need to be reassessed as new information emerges. Regardless, the normative force of these claims makes sense in terms of their positive relationship to the best empirical evidence currently available to us.

A final stipulation: the "pragmatism" of my title is informed by Richard Rorty and his work on Donald Davidson and W.V.O. Quine, and refers to a naturalised, socio/historical, and holistic focus on the relationship between knowers and the worldincluding relationships between scientists and the world (e.g., Rorty 1991; 1991[1987]; 1991 [1988]). Accordingly, we pragmatists view knowers (including ourselves) as ontologically continuous with and co-constitutive of, the world we know-hence the commitment to naturalism. There is nothing to be gained by invoking a non-natural, subjective world of mind, for example, that is inscrutable by definition, that is, in principle, unavailable to natural, public, objective assessment. This naturalist claim is intimately related to a particularly pragmatist take on beliefs: our beliefs about the world arise from complex, historically-contingent, social interactions with, and in, our world-hence the commitment to socio/historicism. And last, this socio/historical claim is applied by pragmatists holistically, i.e., across the board, such that the meaning of any one of our beliefs—normative, scientific, political, personal, technical, emotional-is seen best to be understood by appeal to the empirical conditions that gave rise to the belief in the first place (I modeled this holistic analysis in my presentation of the empirical content of and evidence for the normative feminist political claims, above). For feminist pragmatists interested in science, the empirical conditions of relevance include the inequitable, embodied definition, production, and distribution of the power associated with the practices and knowledge claims of science.

As I am using the term, "pragmatism" then, I mean to shift the burden of proof back on to those who want to make metaphysical, by which I mean non-naturalised, ahistorical, ontologically-robust distinctions between knowers and their world; between minds and bodies; and between a subjective normative realm of political values, and an objective, empirical realm of facts. The truth of these pragmatist claims themselves is yet another layer of contingency, but again these claims are based on the best evidence available to us, or so I shall argue.

Some of the evidence available to us in support of pragmatism comes from seeing the value for feminists of foregrounding a pragmatist perspective when we justify our critically important, political interventions in science. Failures to keep pragmatism in mind lead to a number of intractable epistemic quandaries, including the worry whether and how the justifications for our feminist criticisms of science, produced by feminists, in particular bodies, under particular social descriptions, can be understood by, let alone persuasive to, scientists whose lives are socially constrained/shaped by embodied markers very different from ours. How can we recognise the claims produced by embodied experiences different from ours, especially by those whose embodied 
differences are marginalised? And how do we argue not just that the claims of the marginalised get included in science, but that the marginalised themselves get included? My thesis is that by taking pragmatism seriously, we can show that these quandaries about embodiment pose very difficult practical problems, to be sure, but they are practical problems solvable for and in particular contexts, using tools with which we feminists are already familiar and proficient.

\section{Feminist Epistemology}

The topic of embodiment and the question whether and/or how embodiment limits the kinds of knowledge we can have about ourselves and others is central to a debate between two epistemic positions in feminist philosophy of science, namely, empiricism and standpoint theory. As I mentioned at the beginning of the paper, Wylie's work draws from the standpoint tradition. Kristin Intemann argues persuasively that the feminist empiricist and standpoint positions, at least in their most recent incarnations, are so similar as to be almost indistinguishable (Intemann 2010). However she identifies a commitment to embodiment as a lingering difference between the two-a commitment that, she argues, favours standpoint theory-and so l'll spend some time discussing the debate by way of illustrating my thesis. In particular, I agree with Intemann that feminist empiricism is weaker when it comes to incorporating insights about embodiment, but I argue that a more thorough-going commitment to pragmatism would both strengthen her criticism of feminist empiricism and her support for feminist standpoint theory.

"Feminist empiricism" and "Feminist standpoint" refer to two different rhetorical strategies for showing that and how feminist value-laden interventions in science can actually make science more objective, usually cashed out in terms of increasing empirical adequacy, broadly construed. Although Intemann identifies my pragmatist position as part of the feminist empiricist camp, her description of feminist empiricism is focused primarily on the work of Helen Longino (e.g. Longino 1990). One of my differences with Longino concerns the commitment to what I have called holism. Recall that in my definition of pragmatism, the holism I appealed to involved the claim that the meaning of any one of our beliefs-normative, scientific, political, personal, technical, emotional-is best understood by appeal to the empirical conditions that gave rise to the belief in the first place. According to Longino, political beliefs, feminist or otherwise, are contextual values, operating as normative background assumptions that are not themselves bearers of empirical content (Longino 1990, 75). Normative background assumptions, on her view, are epistemically and ontologically distinct from descriptive, empirical claims. To be sure, Longino recognises that contextual values inevitably have powerful effects on which kinds of empirical data get marshaled as evidence and how that data is described. So, unlike more straightforward empiricist positions, she acknowledges that these kinds of values inevitably play a role in even our most empirically robust scientific theorising. And it is for this reason, she argues, that the contextual values of scientists need to be carefully managed, mostly through interventions at the level of scientific communities and the norms set for organising these communities. For example, Longino argues that science communities must have recognised avenues for criticism and shared standards for evaluation (Longino 1990, p. 76). Longino's suggestions for improving the organisation of scientific communities are 
themselves to be seen as continuous and consistent with the norms of empiricism, thus the label feminist "empiricism."

As Intemann notes, Longino's suggestions about how best to organise scientific communities rest on the entirely reasonable claim that it is easier for us to identify when and where contextual values are influencing scientific reasoning, if those values or interests are different from our own (Intemann, p. 782). This explains why Longino advocates for scientific communities "comprised of individuals with diverse values and interests" (Intemann p. 790). Now, to the question at hand: presumably there is something about the embodied nature of knowledge (with knowledge including, for now, contextual values and interests) that would make a diversity of individual/embodied knowers the best way to ensure a diversity of values and interests, but this presumption is seldom explicitly defended by Longino. For example, one of her prescriptions for the organisation of scientific communities is that there should be an equality of intellectual authority among qualified practitioners (e.g., Longino 1990, p. 78). However, we need also an argument that addresses the historical marginalisation of certain kinds of embodied knowers in science, and society more generally- some kinds of perfectly competent and perhaps even expert knowers are embodied such that they are viewed as incapable of joining the ranks of qualified practitioners among whom intellectual authority must be shared. Longino's view does not explicitly address this problem (Intemann, p. 790).

Intemann also points out a related problem, namely that, for Longino, the increase in objectivity that the scientific community gains when it adopts practices consonant with feminist empiricist prescriptions, seems tied to the inclusion of feminist political values only in cases where there were none before, that is, it is tied only to the increased diversity of views that the presence of feminist values represents. The content of those views is not doing much or any work beyond instrumentally introducing novelty in values as a check on the development of monopolies of background assumptions (Intemann, p. 792). Diversity of values for diversity's sake, seems to be the main goal. So in a science lab where social justice was the norm, sexist values might increase diversity. Must sexist values be included in this case? Intemann is right to be suspicious of any feminist epistemic projects that cannot rule this out.

So insofar as Longino's feminist empiricism is unable to address these problems (the problem that some bodies are inappropriately "pre-screened" out of the pool of intellectual equals, and the problem that the content of contextual values seems less important than their instrumental role as diversity enhancers), Intemann suggests we focus instead on the comparative strengths of feminist standpoint. Intemann notes that for standpoint theory, especially as articulated by Wylie (2003), it is a particular kind of diversity of social position that is promoted as epistemically beneficial in science (Intemann, p. 790). This is partly, says Intemann, because standpoint feminists take knowledge to be embodied, and when power is produced, defined, and distributed relative to an inequitable privileging of some embodied descriptors over others, then appealing to the embodied knowledge of those who have less power can result in more objective and/or more empirically adequate science. Those who are marginalised can, when they organise around that marginalisation, achieve an epistemically privileged vantage. In cases where the marginalisation is relevant to particular scientific theories and practices, then this privileged vantage can produce beliefs that are more objective, 
because more empirically adequate (Wylie 2003). As Intemann explains, "members of marginalised groups are more likely to have had experiences that are particularly epistemically salient for identifying and evaluating assumptions that have been systematically obscured or made less visible as the result of power dynamics" (p. 791).

In contrast to Longino's feminist empiricism, Intemann argues, taking up a feminist standpoint involves paying attention to the differential power relations producing and affecting embodied knowers, and presupposes very particular feminist values, for example, "that oppression is unjust; revealing gender is valuable; and hierarchical power structures ought to be abolished" (Intemann, p. 793). As articulated by Intemann and Wylie, then, feminist standpoint is explicitly committed to the three claims supporting the feminist charge of inequity that I highlighted at the outset. The first claim, that the embodied markers of relevance are socially and historically contingent features of human lives is important to feminist standpoint theory as a reminder that there's no essential kind of body from which a standpoint is achieved. The second claim, that these embodied markers are irrelevant and arbitrary when used as criteria for considering the limits and possibilities of human flourishing, is crucial even or especially when this consideration is being studied in a scientific setting. Finally, to the third claim, that when power is distributed under inequitable social conditions, citizens who are relatively powerless are actively discouraged from investigation of, and commitment to the first two claims. Here we are reminded that achieving an epistemic standpoint really is a political act, in the face of this active discouragement, to gather the evidence of the first two claims and to notice the forces that make recognising the claims so difficult this recognition and knowledge does not come automatically by virtue of being embodied in any particular way.

Intemann concludes her presentation of the benefits of standpoint theory over empiricism by pointing out that on the standpoint view of values, there is good reason to prefer feminist ethical and political commitments over, say, sexist commitments, because the former "are better supported or warranted" (p. 793). So we should include feminist values in our scientific examinations, not for the sake of having a diversity of values, but just in case they are epistemically stronger than available competitors.

What Intemann presents looks to be a good argument for why, where relevant, scientists should listen to, incorporate contributions that contain, or are sensitive to, or at least do not contradict, feminist political values, or claims produced by any group of folks who are politicised about a particular marginalised form of embodied identity. However, I argue that if Intemann had foregrounded a commitment to pragmatism, her argument would be stronger.

\section{Pragmatism}

The first way in which Intemann's account could be strengthened by pragmatism is related to Intemann's diagnosis of problems with Longino's empiricist account. Intemann argues that Longino needs the resources of feminist standpoint to avoid inappropriately reducing the contributions of feminist values to an instrumental role. What is still missing from Intemann's analysis, however, is an argument for why we need not only those feminist contributions but also the presence of the marginalised themselves, who may or may not be making those contributions. Imagine a science community that contains only members who are embodied in privileged ways (most 
science communities at the moment!). Imagine they respond to the inequity of their membership by reading and becoming expert in some of the relevant literature produced by the relevantly marginalised or by attending a conference on issues of inequity, but they stop short of diversifying the membership of their community. How do you then argue not just that the right values, as typically but not exclusively articulated by particular bodies, get included, but that the particular bodies themselves get included? As both Intemann and Wylie have it, the need for and production of feminist values is contingent on a variety of circumstances and is neither needed for every science project, nor produced automatically by virtue of being embodied in any given way (e.g., Wylie 2012, pp. 60-61). This makes good sense, but then it makes it seem as if we don't need an inclusive community of embodied knowers so much as we need the right values for particular projects. Intemann properly wants both. I think a pragmatist analysis will help her here.

Recall the claims about power, embodiment, and inequity outlined at the start. Given that power, including the power associated with the practices and knowledge claims of science, is differentially defined, produced, and distributed according to a normative matrix of embodied markers, and given that we know these embodied markers to be irrelevant and arbitrary when used as criteria for considering the limits and possibilities of human flourishing, then if the bodies that make up science communities reflect the hierarchical distribution of power, we can be confident that differently embodied knowers are being systematically discriminated against in hiring, funding, and support. In these cases, science communities are reflecting inequity; power has not been distributed equitably. Part of the normative feminist project is to encourage a more equitable definition, production, and distribution of that power in scientific settings, as elsewhere.

Adding the holism that I identify with pragmatism helps us recognise that this normative failure of equity is an empirical failure. Just as with the descriptive claims of science, our political beliefs get their meaning and persuasive force in reference to the empirical conditions that give rise to those beliefs. The feminist political charge of inequity is persuasive insofar as it is a claim for which feminists have amassed a great deal of empirical support; failures of this kind of inequity are epistemic failures to consider the weight of the best evidence currently available.

Recall that Longino's view is not pragmatist as l've described it insofar as she does not adopt this holistic approach. Her view is that political beliefs, feminist or otherwise, are non-cognitive values, that is they are not themselves bearers of empirical content, so acting against a political value of equity is not an empirical failure. If feminists are committed only to addressing empirical failures in the ways circumscribed by Longino, then we do not have the resources we need to address the inequitable distribution of power in science communities through the hiring, funding, and support of marginalised bodies.

What we need is to be more holistic in our understanding of what counts as the kinds of evidence to which a good empiricist ought be responsive and that political values have meaning and rhetorical force precisely insofar as they are bearers of empirical content that is consistent with and supportive of other empirical claims we hold true. We need to appreciate that the normative political contribution of feminist theory is co-constitutive with the epistemic project of increasing the empirical adequacy of 
science. On Intemann's account of feminist standpoint theory, feminist values are described as epistemically superior to sexist values, but it is not always clear which values she means here or how they are empirically justified. For example, she writes that "differences in social location that track power relations are clearly likely to produce different sorts of life experiences that can provide relevant empirical evidence for or against certain beliefs or assumptions" (p. 791). Here, feminist values are justified in the sense that they support the inclusion in science of the life experiences of the marginalised, but it is those life experiences that are the bearers of empirical content capable of serving as evidence, not the feminist values themselves. So she does not appeal to the fact that the feminist value of equity is itself a well-supported empirical claim that entails the hiring, funding and support of marginalised bodies. She mentions only that the feminist value of including the (reports of?) the experiences of the marginalised will lead to those experiences serving as empirical evidence for or against particular claims in science

Similarly, Intemann explains that the experiences of members of marginalised groups have "the potential to lead to more rigorous critical reflection because their experiences will often be precisely those that are most needed in identifying problematic background assumptions and revealing limitations with research questions, models or methodologies" (p. 787). In contrast, a pragmatist account of empirical evidence, construed holistically, shows that in fact we have much more direct evidence for the inclusion not only of the experiences of marginalised groups, but of the marginalised themselves, and that is beyond what the marginalised may or may not contribute to the project of identifying background assumptions and the like. Our evidence is the wellsupported empirical inference that not including marginalised knowers is unjust! Intemann's criticisms of feminist empiricism would be strengthened by appeal to the holistic features I have identified as being part of a pragmatist approach.

An additional feature of the pragmatism I endorse, namely naturalism, would also help Intemann in her support of feminist standpoint theory. According to Intemann, feminist empiricists fail to account for the embodiment of knowledge, which leaves us with no justification for the inclusion of feminist values in science. Intemann responds by highlighting the embodied nature of knowledge as articulated by standpoint theory-that the reason feminist values should be included is importantly tied to the ways that those values arise as achieved standpoints in response to embodied experiences of oppression. I think she is exactly right here. But it is also clear that there are certain ways of construing embodiment that set limits on our ability to imagine and share the very content of those values across bodies of different kinds. I should note that Wylie's latest articulations of standpoint theory mostly avoid these epistemic concerns about the limits of subjectivity, but she manages this by downplaying the embodied nature of knowledge (e.g., Wylie 2012). I think Intemann's focus on embodiment is more compelling on this score, especially if accompanied by a pragmatist understanding of what embodied knowledge involves. We need an account of embodiment that shows that and how the justifications for feminist interventions, produced in particular bodies, under particular social descriptions, can be understood by, and persuasive to, scientists whose lives are socially constrained/shaped by embodied markers very different from ours. 
Pragmatists view knowers, bodies and minds, naturalistically, as ontologically continuous with and co-constitutive of, the world we know. Pragmatism involves the claim that there is nothing to be gained by invoking a split between a non-natural, subjective world of mind, and an ontologically distinct natural world of bodies. Applied to embodied claims of knowledge, pragmatists think we have no good reason to think that knowledge, however embodied, is inscrutable by definition, that is, in principle, unavailable to natural, public, objective assessment. Put another way, there is no metaphysically private, inaccessible "inside" experience available to some bodies, but to which "outsiders," those differently embodied, have no epistemic access. The activity of knowing, moving around in our worlds, giving content to our variously embodied experiences, arises and shifts in a continual interplay with other bodies, even as we communicate and work with each other to reveal the ways that power is inequitably embodied.

\section{Communicating Across Bodies}

There are a number of areas of feminist research on embodiment outside of the feminist epistemology literature that chime well with this pragmatist approach and can provide resources for feminist philosophers of science for thinking about how knowledge is embodied but not radically subjective, nor metaphysically mysterious and inscrutable. The main lesson is that the problems of embodiment are solvable for and in particular contexts, using tools with which we feminists are already familiar and proficient.

Anthropologist and midwife Melissa Cheyney has discussed the embodied knowledge claims arising in the context of pregnancy and childbirth (Cheyney 2008). Part of what women who choose to give birth at home are doing is trusting their embodied knowledge (sometimes referred to as trusting their "intuitions"). Note though that these intuitions are not inaccessible nor are their origins mysteriously subjective and inscrutable. One woman in Cheyney's study explained how at some point in her home delivery she came to know that she should get out of bed and walk around the house, lifting her knees high in an exaggerated march. The woman's midwife later explained to her that this was a good thing as it helped the baby's head to reposition in the birth canal. The mother's embodied knowledge had been successfully communicated to the midwife and confirmed by shared experience with other mothers and their babies. The embodied genesis of the mother's "intuition" can and should be respected and encouraged as reliably authoritative.

Those of Cheyney's respondents who had their first delivery in a (very traditional) hospital setting reported how the environment encouraged in them an epistemic passivity. For better or worse, they became the focus of the knowledge claims of the experts who surrounded them, and they felt that they gave up some of their own epistemic authority. The point of epidurals, for example, is to limit the mother's access to her embodied knowledge (such as the knowledge of pain, which in many cases is a very good thing indeed). What we are learning is that, regardless of where a mother chooses to give birth, being pregnant and giving birth makes a difference to the (kinds of) knowledge available to that woman, to her midwives, and her doctors, at any given moment, and this knowledge, based on these women's embodied experiences, should inform medical research on childbirth. The reason that those of us who are not currently or are unable ever to be pregnant can still learn about and from this embodied 
phenomenon is a feature of the interactions of women and their care providers. The very activities that give rise to the embodied knowledge provide us a way in to sharing and learning from that knowledge. Even as Cheyney argues for the epistemic differences between the differently embodied mother, midwife, and doctor, this difference is made available through Cheyney's successful communication with her respondents. The differential embodied experiences of birthing in a hospital versus birthing at home provides the very entry point for epistemic evaluation of those embodied differences for the women respondents, for Cheyney, and for us, her readers.

Philosopher Jackie Leach Scully writes about the limits of the "moral imagination," between people who are differently embodied with respect to physical and mental abilities. In "Moral Imagination, Disability, and Embodiment" (2007), Catriona Mackenzie and Scully argue that there are barriers to imagining oneself differently situated, or imagining being another person, arising in part from the way imagination is constrained by embodied experience. However, they continue, these barriers do not mean there is no role for the imaginative engagement with others; while we can never understand the other 'from the inside' we can make use of imaginative engagement to "expand the scope of our moral sympathies" (p. 346). The appeal to the "inside" here seems not to be a metaphysical stumbling block to interpretation, but more a caution against presuming that experiences are identical across bodies and knowers. So research on disability, for example, needs to start from the lives of the disabled, precisely because talking across abilities reveals chasms of difference.

Another compelling discussion of embodiment comes from Protevi's work, inspired in part by Iris Marion Young's germinal essay on the topic "Throwing Like a Girl" (2005). For example, in his essay "Affect, Agency and Responsibility," Protevi discusses the role of the very exhaustive and exhausting military training regimes-public, objective processes - that are required to get many infantry soldiers to overcome empathy and fear, in order to kill combatants (2008). It turns out that it is harder to get most people to kill each other at close range than we might have thought. However, the regimes are so effective that many individual soldiers come to embody the training and achieve the capacity to kill. Protevi argues that in many cases the ability to kill is in fact an emergent property of the military group in question. What looks to be a very private, embodied, subjective decision and action, that of killing, is in fact only possible because of a public, objective group training regime designed to overcome wide-spread inhibitions on killing. Studying the training regimes gives us epistemic access to a deeply embodied experience.

\section{Conclusion}

I have argued that foregrounding the naturalised, socio-historic, and holistic elements of pragmatism helps feminists better justify our critically important, political interventions in science. In particular, the holistic aspect I identify with pragmatism helps us see the empirical evidence supporting our political claim for the inclusion in science of embodied knowers who have been historically marginalised in science. We need this kind of holistic account to show that and how a failure to respond to this political claim, a failure to include embodied knowers who have been historically marginalised, is an epistemic failure to which empirically-minded scientists should attend. The naturalism of my approach responds to the apparent contradictions that sometimes arise in accounts 
of standpoint theory that focus on the embodied features of knowledge. We need not just to dismiss these contradictions, but to argue that embodied knowledge is a communicative affair arising from entirely natural processes - that standpoint theory is naturalised through and through, and does not (indeed cannot) invoke non-natural, private subjects, forever separated from the natural world, and each other. As mothers write of their differently embodied knowledge, as women who are differently-abled successfully communicate the facts of their difference, as soldiers report on their feelings of remorse and guilt at killing, the very fact of their communicative success is revealing of and indeed premised on publicly accessible, shared interactions with and in the world; a shared world against which these embodied experiences are articulated, within which differently embodied values can be heard, seen, felt, understood, and justified-or not justified, as the case may be. When there are failures of justification, and the fact of continued inequities in power shows these failures to be very real, the failures are the product of practical, material limits-limits to our sympathy and patience, for example-but not to limits defined in terms of metaphysical incommensurability, not to limits in our ability to understand, and to know. Foregrounding pragmatism helps make embodiment make sense.

\section{Acknowledgements:}

My thanks first to Michelle Pham for helping me see that an argument for including the marginalised, in addition to including their knowledge, is often missing in feminist standpoint theory. Thanks to Kristen Intemann, Alison Wylie, and Helen Longino for provoking me with their great work. Thanks also to an anonymous referee for charitably identifying ways to strengthen the paper. Finally, thanks to John Protevi, Stephanie Jenkins, Sione Filimoehala, and Jonathan Kaplan for their comments on earlier drafts.

\section{References:}

Cheyney, Melissa J. 2008. "Homebirth as Systems-Challenging Praxis: Knowledge, Power, and Intimacy in the Birthplace." Qualitative Health Research 18 (2): 254267.

Clough, Sharyn and Bill Loges. 2008. "Racist Value Judgments as Objectively False Beliefs: A Philosophical and Social-Psychological Analysis." The Journal of Social Philosophy 39 (1): 77-95.

Clough, Sharyn. 2010. "Drawing Battle Lines and Choosing Bedfellows: Rorty, Relativism, and Feminist Strategy." In Feminist Interpretations of Richard Rorty, ed. Marianne Janack, College Park, PA: Penn State Press, pp 155-172.

Intemann, Kristin. 2010. "25 years of Feminist Empiricism and Standpoint Theory: Where Are We Now?" Hypatia 25 (4): 778-796.

Longino, Helen. 1990. Science as Social Knowledge. Princeton: Princeton University Press.

Mackenzie, Catriona and Jackie Leach Scully. 2007. "Moral Imagination, Disability, and Embodiment." Journal of Applied Philosophy 24 (4): 335-351.

Protevi, John. 2008. "Affect, Agency and Responsibility: The Act of Killing in the Age of Cyborgs." Phenomenology and the Cognitive Sciences 7(3): 405-413. 
Rorty, Richard. 1991 [1987]. "Science as Solidarity." Reprinted in Philosophical papers Vol. 1, Objectivity, Relativism, and Truth. Cambridge: Cambridge University Press.

----- 1991 [1988]. “Is Natural Science a Natural Kind?" Reprinted in Philosophical papers Vol. 1, Objectivity, Relativism, and Truth. Cambridge: Cambridge University Press.

----- 1991. "Inquiry as Recontextualization: An Anti-dualist Account of Interpretation." In Philosophical Papers Vol. 1, Objectivity, Relativism, and Truth. Cambridge: Cambridge University Press.

Wylie, Alison. 2012. "Feminist Philosophy of Science: Standpoint Matters," APA Presidential Address, in Proceedings and Addresses of the APA 86(2): 46-76.

------. 2003. "Why Standpoint Matters." In Science and Other Cultures: Issues in Philosophies of Science and Technology, ed. Robert Figueroa and Sandra Harding. New York: Routledge.

Young, Iris Marion. 2005. On Female Body Experience: "Throwing Like a Girl" and Other Essays. Oxford: Oxford University Press.

Wylie, Alison and Lynn Hankinson Nelson. 2007. Coming to Terms with the Values of Science: Insights from Feminist Science Studies Scholarship. In Harold Kincaid, John Dupré, and Alison Wylie (eds.), Value-Free Science? Ideals and Illusions. Oxford: Oxford University Press. 